\title{
Dietary factors associated with preeclampsia or eclampsia among women in delivery care services in Addis Ababa, Ethiopia: a case control study
}

\author{
Teklit Grum ${ }^{1 *} \mathbb{D}$, Solomon Hintsa ${ }^{2}$ and Gebremedhin Hagos ${ }^{3}$
}

\begin{abstract}
Objective: Preeclampsia or eclampsia, which is one of the direct obstetric complication, results in maternal and child morbidity and mortality. The factors associated with it remains unclear. So, the aim of the study was to assess the dietary factors associated with preeclampsia or eclampsia among women in delivery care services in Addis Ababa, Ethiopia.

Results: Factors which were investigated as protective for preeclampsia or eclampsia were: Fruit intake during pregnancy (AOR: 0.94, 95\% Cl 0.20, 4.32), vegetable intake during pregnancy (AOR: 0.95, 95\% Cl 0.01, 0.71) and receiving nutritional counseling during antenatal care (AOR: $0.17,95 \% \mathrm{Cl} 0.05,0.6)$. In the other side being nulliparous women was a risk factor for preeclampsia or eclampsia (AOR: 2.02, 95\% Cl 1.15, 3.55).
\end{abstract}

Keywords: Dietary factors, Preeclampsia or eclampsia, Women, Ethiopia

\section{Introduction}

Preeclampsia is a syndrome characterized by hypertensive disorder and protein in the urine which usually occurs after 20 weeks of gestational age whereas eclampsia is the severest form of preeclampsia [1]. Its' causes remains unclear and was responsible for many maternal and infants morbidity and mortality which accounts 5-10\% worldwide [2]. Even though the magnitude of preeclampsia and eclampsia varies among countries, the burden is higher in developing than in developed countries [3].

In Ethiopia, preeclampsia and eclampsia is one of the major obstetric complications and was the most requirement for referral before onset of labour which accounts $83 \%$ [4].

It is obvious that pregnant women needs a healthy nutrition not only for the health of pregnant women but

\footnotetext{
*Correspondence: teklitvip@gmail.com

1 Department of Reproductive Health, College of Health Sciences, Aksum University, Aksum, Ethiopia

Full list of author information is available at the end of the article
}

also for the child health [1]. Studies indicated that dietary habits are associated with preeclampsia and eclampsia [5-9]. Since, there are limited and inconsistence among the studies finding, this study will have its own contribution on assessment of factors associated with preeclampsia/eclampsia.

\section{Main text}

Study design

Facility based unmatched case control study was conducted.

\section{Study period and area}

The study was conducted from December, 2015 G.C. to February, 2016 G.C. in two public hospitals in Addis Ababa, Ethiopia. Addis Ababa, where African Union is located, hosts an estimated 3.238 million people [10]. According to the city administration health bureau, the health coverage was $100 \%$. Under the city administration there are 6 public hospitals and the study was conducted 
in 2 hospitals namely Zewditu Memorial Hospital and Ghandi Memorial Hospital.

\section{Inclusion criteria}

Pregnant women with blood pressure of $>140 / 90$ and presence of protein in urine was inclusion criteria for cases [1] and pregnant women who were not diagnosed for preeclampsia and eclampsia were controls. The inclusion criteria of gestational age for both groups were after 28 weeks.

\section{Exclusion criteria}

Pregnant women with known hypertension and renal disease were excluded from the study.

\section{Sample size determination}

Double population proportion formula was used to estimate the sample size using Epi-info 7 by considering the lowest adjusted odds ratio (2.34) and the proportion of exposed group in controls was $(36.2 \%)$ from the Bahir Dar city study [6] which revealed unable to read and write was a risk factor for preeclampsia/eclampsia. During the sample size determination assumptions: $95 \%$ level of confidence, $5 \%$ marginal error and $80 \%$ power was considered. So, it was calculated to be 221 and after adding $10 \%$ for possible non-responses, the final sample size was estimated as 243 ( 81 cases and 162 controls).

\section{Sampling and data collection procedure}

We select two public hospitals with largest delivery care load from the six hospitals under the city administration (Zewditu Memorial Hospital and Ghandi Memorial Hospital). Regarding to selection of the study subjects, all cases that diagnosed consecutively were included in the study. Once the case is diagnosed, two controls were selected immediately by simple random sampling technique and using delivery register as frame list.

Structured and pretested questionnaire was used to collect data by face to face interview. The questionnaire was initially prepared in English and translated to offcial language (Amharic). Four diploma holder midwifery were hired as data collectors and were supervised by two bachelor of sciences in midwifery. We use a quarter delivery report prior to study during allocation of proportional to size between the two hospitals. So, the Ghandi Memorial Hospital and Zewditu Memorial Hospital have quarter delivery report of 1496 and 1110 respectively. Accordingly, 138 (46 cases and 92 controls) study subjects from Ghandi Memorial Hospital and 105 (35 cases and 70 controls) form Zewditu Memorial Hospital were participated in the study.

\section{Data analysis procedure}

The data was entered using Epi-info 7 and transferred to STATA 14 for further cleaning and analysis. Both Bivariable and multi variable analysis was done to see the association between the independent and dependent variables. Variance inflation factor (VIF) was checked for possible multi-colinearity among the variables. The model fitness for the logistic regression was checked using Hosmer and Lemeshow goodness of fit test statistics. Variables with p-value $<0.05$ in the Bivariable analysis where included in the multivariable analysis to control confounding factors. Finally variables with p-value $<0.05$ in the multivariable analysis was declared as a significant association with preeclampsia/eclampsia.

\section{Results}

\section{Socio-demographic characteristics of study participants}

All participants (81 cases and 162 controls) respond to the study with response rate of $100 \%$. The mean age of study participants was 27.22 years old with standard deviation of 5.03 and $81.07 \%$ of them belongs to $20-34$ years age group. One hundred thirty-eight $(56.79 \%)$ and 88 (36.21\%) of the study subjects were orthodox followers and from Amhara ethnicity respectively. Concerning to educational status, only 24 (9.88\%) of the participants had never attend formal education. The majority of the participants, 21 (82.72\%) were married similarly 99 (40.74\%) of the participants were housewife. The average monthly income of the study participants was 2921 Ethiopian Birr and nearly half of them had less than average (Table 1).

The variables checked for possible association with preeclampsia or eclampsia but were not significant in Bivariable analysis were; educational level, occupation, antenatal care follow up, history of abortion, history of stillbirth, cigarette smoking during pregnancy and chewing kchat during pregnancy. Having preeclampsia or eclampsia in previous pregnancy was significantly associated with preeclampsia or eclampsia in bivariate analysis (COR: 2.86, 95\% CI 1.07, 7.65) but it remains insignificant in the multivariable analysis. Similarly, drinking coffee daily was associated with preeclampsia or eclampsia in bivariate analysis only (COR: $3.26,95 \%$ CI 0.42, 25.36).

Receiving nutritional counseling during antenatal care follow up was found that protective for preeclampsia or eclampsia in the multivariable analysis (AOR: 0.17, $95 \%$ CI 0.05, 0.6). Being nulliparous was also associated with preeclampsia or eclampsia. The odds of developing preeclampsia or eclampsia in nulliparous women was 2.02 times higher than women with one or more parity (AOR: 2.02, 95\% CI 1.15, 3.55). Regarding to pregnancy interval, women who had $<1$ year pregnancy interval was at risk of developing preeclampsia or eclampsia 
Table 1 Socio-demographic characteristics of women attending delivery care in Addis Ababa, Ethiopia 2016 G.C

\begin{tabular}{|c|c|c|}
\hline Variables & Frequency & Percent \\
\hline \multicolumn{3}{|l|}{ Age in years } \\
\hline$<20$ & 18 & 7.41 \\
\hline $20-34$ & 197 & 81.07 \\
\hline$\geq 35$ & 28 & 11.52 \\
\hline \multicolumn{3}{|l|}{ Mean age $=27.22 \pm 5.03$} \\
\hline \multicolumn{3}{|l|}{ Religion } \\
\hline Orthodox & 138 & 56.79 \\
\hline Muslim & 58 & 23.87 \\
\hline Protestant & 30 & 12.35 \\
\hline Others & 17 & 7 \\
\hline \multicolumn{3}{|l|}{ Ethnicity } \\
\hline Amhara & 88 & 36.21 \\
\hline Oromo & 68 & 27.98 \\
\hline Gurage & 36 & 14.81 \\
\hline Tigray & 32 & 13.17 \\
\hline Others & 19 & 7.8 \\
\hline \multicolumn{3}{|l|}{ Attending formal education } \\
\hline Yes & 219 & 90.12 \\
\hline No & 24 & 9.88 \\
\hline \multicolumn{3}{|l|}{ Marital status } \\
\hline Never married & 21 & 8.64 \\
\hline Married or living together & 201 & 82.72 \\
\hline Others & 21 & 8.64 \\
\hline \multicolumn{3}{|l|}{ Occupation } \\
\hline Housewife & 99 & 40.74 \\
\hline Merchant & 46 & 18.93 \\
\hline Employee & 78 & 32.10 \\
\hline Student & 20 & 8.23 \\
\hline \multicolumn{3}{|l|}{ Income (ETB) } \\
\hline$\leq 2921$ & 118 & 48.56 \\
\hline$>2921$ & 125 & 51.44 \\
\hline
\end{tabular}

comparing to women who had $>1$ years pregnancy interval (AOR: 4.43, 95\% CI 1.78, 11.04). Fruit and vegetable intake during pregnancy was a protective factor for preeclampsia or eclampsia independently. Comparing to women who didn't eat fruit or vegetables, women who ate fruit or vegetable daily were less risk of developing preeclampsia or eclampsia (AOR: $0.94,95 \%$ CI 0.20, 4.32) and (AOR: 0.95, 95\% CI 0.01, 0.71) respectively (Table 2).

\section{Discussion}

We tried to investigate dietary intake during pregnancy factors associated with preeclampsia or eclampsia. As we expected, we found that fruit and vegetables intake during pregnancy as well as a healthy diet counseling during early antenatal care follow up were associated with reduction of preeclampsia or eclampsia. Besides, even though our primary aim was investigating dietary habits as a factor or not for preeclampsia or eclampsia development, we identified pregnancy interval with $<1$ year and being nulliparous women as a risk factor for the outcome.

This finding revealed that nutritional counseling during pregnancy was associated with reduction of preeclampsia or eclampsia development. The odds of developing preeclampsia/eclampsia in pregnant women who took fruit daily during pregnancy were less comparing to pregnant women who didn't take fruit during pregnancy (AOR: 0.94, 95\% CI 0.20, 4.32).

During counseling on healthy diet, it addresses a wide range of nutritional values. For example, nutritional counseling on healthy dietary advice to consume vegetables and fruit benefit with regard to prevention of preeclampsia or eclampsia. Pregnancy is a period when most women are highly motivated for dietary advice. Because changes toward a healthier diet may also benefit their children $[7,9]$. Dietary changes have a low cost, low risk compared with medical interventions, and have advantage beyond prevention of preeclampsia in public health importance.

Nulliparous women was at risk of having preeclampsia or eclampsia in this finding. Similarly a nested case-control study in Norway [11] investigated that nulliparous is a risk factor for preeclampsia. Unlike to this finding, a prospective study [12] indicates that being nulliparous is not a risk factor for preeclampsia.

Pregnancy interval was associated with preeclampsia or eclampsia. Pregnant women with $<1$ year pregnancy interval was at higher risk of developing preeclampsia/ eclampsia than pregnant women with $>1$ pregnancy interval. In contrast, study on the assessment of risk factors made based on suggestive symptoms of preeclampsia, pregnancy interval was not associated with preeclampsia or eclampsia [13]. The inconsistency between the studies may be in the variation of preeclampsia diagnosis. Since the cases in that study was diagnosed by suggestive symptoms unlike to this study.

Fruit and vegetable intake during pregnancy was also found as protective factor for preeclampsia or eclampsia in this study. Fruit and vegetable dietary which are rich of vitamin $\mathrm{C}$ and vitamin $\mathrm{E}$ are associated with preeclampsia reduction. The prevention of these vitamins from preeclampsia development is due their anti-oxidant effects $[9,14]$.

The presence of high anti-oxidants in the plasma and placenta prevents hypo perfusion. As a result, the required level of these anti-oxidants enables endothelial cell to function normally. Following that hypertension and proteinuria, which are the clinical symptoms of preeclampsia, will not be developed [14]. 
Table 2 Bivariable and multivariable analysis of women attending delivery care in Addis Ababa, Ethiopia 2016 G.C

\begin{tabular}{|c|c|c|c|c|}
\hline \multirow[t]{2}{*}{ Variables } & \multicolumn{2}{|c|}{ Preeclampsia or eclampsia } & \multirow[t]{2}{*}{$\operatorname{COR}(95 \%, \mathrm{Cl})$} & \multirow[t]{2}{*}{$\operatorname{AOR}(95 \%, \mathrm{Cl})$} \\
\hline & Yes (\%) & No (\%) & & \\
\hline \multicolumn{5}{|l|}{ Previous preeclampsia } \\
\hline No & $26(74.29)$ & $91(89.22)$ & 1 & 1 \\
\hline Yes & $9(25.71)$ & $11(10.78)$ & $2.86(1.07,7.65)$ & $2.64(0.77,9.0)$ \\
\hline \multicolumn{5}{|c|}{ Nutritional counseling during ANC } \\
\hline No & $32(43.24)$ & $17(10.9)$ & 1 & 1 \\
\hline Yes & $42(56.76)$ & $139(89.1)$ & $0.16(0.08,0.32)$ & $0.17(0.05,0.6)^{*}$ \\
\hline \multicolumn{5}{|l|}{ Parity } \\
\hline Nulliparous & $47(58.02)$ & $64(39.51)$ & $2.12(1.23,3.64)$ & $2.02(1.15,3.55)^{*}$ \\
\hline$\geq 1$ parity & $34(41.98)$ & $98(60.49)$ & 1 & 1 \\
\hline \multicolumn{5}{|l|}{ Pregnancy interval (year) } \\
\hline$<1$ & $13(37.14)$ & $12(11.76)$ & $6.56(2.14,20.06)$ & $4.43(1.78,11.04)^{*}$ \\
\hline$\geq 1$ & $22(62.86)$ & $90(88.24)$ & 1 & 1 \\
\hline \multicolumn{5}{|l|}{ Fruit intake } \\
\hline No & $22(27.16)$ & $10(6.17)$ & 1 & 1 \\
\hline Daily & $15(18.52)$ & $41(25.31)$ & $0.17(0.06,0.43)$ & $0.94(0.20,4.32)^{*}$ \\
\hline At least once per week & $44(54.32)$ & $111(68.52)$ & $0.18(0.09,0.41)$ & $0.23(0.06,0.91)^{*}$ \\
\hline \multicolumn{5}{|l|}{ Vegetable intake } \\
\hline No & $15(18.52)$ & $5(3.09)$ & 1 & 1 \\
\hline Daily & $6(7.41)$ & $35(21.60)$ & $0.57(0.02,0.22)$ & $0.95(0.01,0.71)^{*}$ \\
\hline At least once per week & $60(74.07)$ & $122(75.31)$ & $0.164(0.06,0.47)$ & $0.25(0.05,1.37)$ \\
\hline \multicolumn{5}{|l|}{ Coffee intake } \\
\hline No & $23(28.40)$ & $84(51.85)$ & 1 & 1 \\
\hline Daily & $32(39.51)$ & $26(16.05)$ & $4.5(2.25,9.0)$ & $3.26(0.42,25.36)$ \\
\hline At least once per week & $26(32.10)$ & $52(32.1)$ & $1.83(0.95,3.53)$ & $5.09(0.93,27.97)$ \\
\hline
\end{tabular}

COR crude odds ratio, $A O R$ adjusted odds ratio

* $\mathrm{p}$-value $<0.05$

\section{Conclusion and recommendation}

This study mainly revealed that the role of dietary factors on the prevention of preeclampsia or eclampsia. Fruit and vegetable intake as well as receiving nutritional counseling during early pregnancy has a role on reduction of preeclampsia or eclampsia development. In another way being nulliparous women was identified as a risk factor for preeclampsia or eclampsia.

As recommendation, pregnant women should take fruit and vegetables starting from early pregnancy. Health providers should give nutritional counseling for pregnant women during antenatal care follow up. In addition to that, health providers should give focus for nulliparous while screening for preeclampsia or eclampsia.

\section{Limitations}

As the limitation of the study, the amount of fruit and vegetable intake by pregnant women during pregnancy were not measured. In addition to that, even though preeclampsia or eclampsia can develop during postpartum period rarely, the cases were not followed after discharge.

\section{Authors' contributions}

TG contributed on the design, data interpretation and writing of the study. $\mathrm{SH}$ and GH contributed on data analysis and write up. All authors read and approved the final manuscript.

\section{Author details}

${ }^{1}$ Department of Reproductive Health, College of Health Sciences, Aksum University, Aksum, Ethiopia. ${ }^{2}$ Department of Epidemiology and Biostatistics, College of Health Sciences, Aksum University, Aksum, Ethiopia. ${ }^{3}$ Department of Medical Science, College of Health Sciences, Aksum University, Aksum, Ethiopia.

\section{Acknowledgements}

We would like to thank Addis Ababa University for financial support of this study. Our thanks goes to Ghandi Memorial Hospital and Zewditu Memorial Hospital for their cooperation while we doing this study in their institution. Finally, we would like to thank the study subjects, data collectors and supervisors for their voluntariness in participating this study.

\section{Competing interests}

The authors declare that they have no competing interests. 


\section{Availability of data and materials}

All data generated or analyzed during this study is available on request from the corresponding author.

\section{Consent for publication}

Not applicable.

\section{Ethics approval and consent to participate}

The study was approved by Institutional Review Board College of Health Science Addis Ababa University. Zewditu Memorial Hospital and Ghandi memorial Hospital was communicated through official letter for their permission. In addition to that written informed consent was done for the study subjects and for participant below 18 years old consent was taken from their mothers/ fathers.

\section{Funding}

This research work has been funded by Addis Ababa University.

\section{Publisher's Note}

Springer Nature remains neutral with regard to jurisdictional claims in published maps and institutional affiliations.

Received: 21 August 2018 Accepted: 25 September 2018

Published online: 01 October 2018

\section{References}

1. Brown LS. Nutritional requirement during pregnancy. Boston: Jones and Bartlett publishers, LLC; 2009.

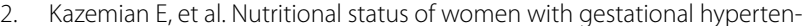
sion compared to normal pregnant women. Women's Health Care. 2012. https://doi.org/10.3109/10641955.2013.784782.
3. Harutyunyan A, Armenian H, Petrosyan V. Interbirth interval and history of previous preeclampsia: a case-control study among multiparous women. BMC Pregnancy Child Birth. 2013;13:244.

4. Ethiopian Public Health Institute. Ethiopian emergency obstetric and newborn care (EmONC) assessment. Ethiopia: Addis Ababa; 2016.

5. Chunfang $Q$, et al. Dietary fiber intake in early pregnancy and risk of subsequent preeclampsia. Am J Hypertens. 2008;21:903-9.

6. Endeshaw $M$, et al. Effect of maternal nutrition and dietary habits on preeclampsia: a case-control study. Int J Clin Med. 2014:5:1405-16.

7. Jodie MD, Cecelia OB, Rosalie MG. Preventing pre-eclampsia_are dietary factors the key? BMC Med. 2014;12:176.

8. Kiondo P, et al. Risk factors for pre-eclampsia in Mulago Hospital, Kampala, Uganda. Trop Med Int Health. 2012;17(4):480-7.

9. Meltzer HM, et al. Effect of dietary factors in pregnancy on risk of pregnancy complications: results from the Norwegian mother and child cohort study. Am J Clin Nutr. 2011;94(suppl_6):1970S-4S.

10. Spaliviero M, Cheru F. The state of Addis Ababa: the Addis Ababa we want. UN-Habitat: Addis Ababa; 2017.

11. Rmnaug $A B$, et al. Risk factors and clinical manifestations of pre-eclampsia. Br J Obstet Gynaecol. 2000;107:1410-6.

12. Chappell $L C$, et al. Adverse perinatal outcomes and risk factors for preeclampsia in women with chronic hypertension: a prospective study. J Am Heart Assoc. 2008;51:1002-9.

13. Agrawal S, Walia GK. Prevalence and risk factors for symptoms suggestive of preeclampsia in Indian women. J Women's Health. 2014;3(6):2-9.

14. Rajaee M, Alizadeh A, Roozbeh N, Salemi M, Falahat A. The role of nutrition in the prevention of pre-eclampsia and related mechanisms-a review article. VISI J Akademik. 2015;7:4-8
Ready to submit your research? Choose BMC and benefit from

- fast, convenient online submission

- thorough peer review by experienced researchers in your field

- rapid publication on acceptance

- support for research data, including large and complex data types

- gold Open Access which fosters wider collaboration and increased citations

- maximum visibility for your research: over $100 \mathrm{M}$ website views per year

At BMC, research is always in progress.

Learn more biomedcentral.com/submissions 